\title{
Experimental Characterisation of the Mechanical Properties of Lightweight 3D Printed Polymer Materials for Biomechanical Application in Ankle-Foot Orthosis
}

\begin{abstract}
RADU CALIN PAHONIE ${ }^{1}$, AMADO STEFAN ${ }^{1}$, IOANA RALUCA ADOCHIEI ${ }^{1}$, CARMEN LUIZA COSTULEANU², GABRIELA GLADIOLA ANDRUSEAC 3 , GEORGE UNGUREANU2, DRAGOS PETRICA SARDARU3*

${ }_{1}^{1}$ Military Technical Academy, 39-49 George Cosbuc Blvd, 040531, Bucharest, Romania

2 Ion Ionescu de la Brad University of Agricultural Sciences and Veterinary Medicine of lasi, Department of Agrobusiness,

3 Mihail Sadoveanu Alley, 700490, lasi, Romania

${ }^{3}$ Grigore T. Popa University of Medicine and Pharmacy lasi, Romania, Department of Biomedical Science, 16 Universitatii Str., 700115, lasi, Romania

In lumbar disc herniation a possible functional problem in the ambulation is the Foot-drop syndrome caused by radicular nerve pinching. This causes a dramatic loss in gait cycle efficiency. In the rehabilitation process patients may benefit from wearing a foot orthosis that prevents them from falling and secondary injuries. Evidence in the literature suggests the important correlation between the optimal match of the forces produced during human gait and the rigidity of the constructive materials. The inherentrigidity of the materials plays an important role in determining its biomechanical functions. The paper proposes an experimental and numerical characterization of 3D printed $A B S$ and $P L A$ specimens using a universal traction-compression testing machine and a finite element method numerical simulation.
\end{abstract}

Keywords: lumbar disc herniation, paretic sciatica, 3D printing, infill, ABS, PLA, mechanical characteristics

The lastfew years have seen an increasingly widespread use of rapid prototyping techniques, of which the most frequentis the Fused Deposition Modeling technology using 3D printers, also referred to as 3D printing. This method consists of laying down, layer by layer of molten material, usually different types of polymer materials, to produce a previously designed CAD (Computer Aided Designed) part. This new printing technology is making its way into the biomechanical field with unique custom developed applications for medical patients in need. Such is the case of $3 \mathrm{~d}$ printed ankle-foot orthosis.

The disease that needs to be addressed, the paretic ankle dorsiflexion, can be the result of degenerative lumbar spinal diseases. In clinical settings, muscular weakness is tested with manual muscle test technique (MMT). Muscle force is tested on a scale from 0 to 5.0 meaning no force and 5 maximum force as described by British Medical Research Council [1]. In this case, the patients are diagnosed with foot drop syndrome if the muscular force of the tibialis anterior and extensor hallucis longus muscles is $\leq 3$ [2].

Lumbar disc herniation and neural foramina stenosis are the two most encountered causes of paretic ankle dorsiflexion. In a report of 46 cases of ankle dorsiflexion weakness related to lumbar disc diseases, $52 \%$ were related to lumbar disc herniation and only $35 \%$ due to spinal stenosis. In other two reports, $57 \%$ of patients diagnosed with paretic ankle dorsiflexion were due to lumbar disc herniation, and the rest had lumbar spinal stenosis $[3,4]$.

When the origin of the paretic dorsiflexion is centered on the peripheral nervous system, the cause may be the compression of the spinal nerve at the radicular level. The most common involved spinal level is L4/L5 (L5 root) followed by L5/S1 (S1 or L5 root) [2].

The incidence of the paretic dorsiflexion in patients with lumbar disc herniation is not well established because it is dependent on the group of the patients studied. It has been estimated that complete paralysis and a severe motor deficit of ankle dorsiflexion can be present in up to 4.4$6.4 \%$ subjects with lumbar disc herniation candidates for surgical treatment of nerve root compression [5].

For normal human gait cycle, the paretic ankle dorsiflexion translates into the modification of the swing and mid-stance phases. In the swing phase of the gait cycle failure to activate foot dorsiflexion can lead to falls and injuries.

Patients with paretic ankle dorsiflexion may benefit from wearing a foot orthoses to aid in walking and prevent slipping. Depending on the material that is made some ankle foot orthoses can be fitted inside the shoes to minimize the inconvenience [6]. Orthoses are defined as external devices utilized on a body segment to prevent and correct a segmental pathological movement.

These devices work by transferring forces to the segmental body to oppose or assist a movement, to move the power or to protect the articulation. In current clinical application, ankle foot orthoses are produced from a variety of thermoplastic materials such as polypropylene. The materials used in the method of fabrication plays a significant role in improving pathological gait [7].

Evidence in the literature suggests the great correlation between the optimal match of the forces produced during human gait and the rigidity of the valuable materials $[8,9]$. The rigidity of the component materials has been in general measured with the use of various parameters such as stiffness, resistive moments and strains. The inherent stiffness of the materials plays a significant role in determining its biomechanical functions [10-14].

The aim of this article is to offer an experimental and numerical characterization of $3 D$ printed $A B S$ and PAL specimens using a universal traction-compression testing machine. After the material data has been gathered, a numerical study using ACP module of ANSYS 16.0 is 
undertaken to compare samples printed under differentinfill percentages and to explore the way this affects the material strength and its implication in orthosis developmentis regarded through data comparison. A novel approach is offered by treating the specimen as a composite material and each printing layer as a ply. The advantages and challenges of such a proposition are then discussed.

The progress of prototyping technology has generated an accelerated development of 3D printing [15-17]. 3D printing is currently used by advanced applications such as adaptive structures made of shape memory polymers, as well as by custom made little impactresearch applications such as airfoil design for wind tunnel tests. This increased popularity has focused equal attention on the study of 3D printing techniques, as the deeper understanding of the mechanical properties and characteristics of the designed parts became increasingly important. Individual studies focused on ASTM standard tensile tests to ascertain the tensile properties of the model as a function of the build characteristics (form, raster orientation, etc.) $[18,19]$, while others considered researchingthe creation of polymeric blends at the cost of the material strength reduction in order to solve 3D printed material anisotropy problems [20, 21].

However, this paper proposes the study of the infill characteristics and their impact on the polymer specimens' tensile strength.

\section{Experimental part}

This CAD partis usually exported as a stereolithographyfile and used by the printer's software to generate the part's layers of specific height. The printing process is based on the file produced by the printer's software (usually as G-code) and the extrusion of material.

The printing filaments used for this study were acrylonitrile butadiene styrene (ABS) and polylactic acid (PAL).

The extrusion is a four step process that takes place as follows (fig. 1):

-a material filament is fed into the printer's head using feeding rollers;

-the heaters raise the temperature of the filament tot the materials melting point, and the flow begins;

-the material flows through an interchangeable nozzle with a standard diameter tip (e.g. $0.4,0.6$ or $0.8 \mathrm{~mm}$ );

-the entire feeder assembly moves according to the stacking sequence in the XY plane until a layer is generated, then it moves on the z-axis with the height of the filament to start the nextlayer.

A road represents the accepted definition of a single line of extruded and deposited material, while a layer is a summation of all side by side roads in the same working plane.

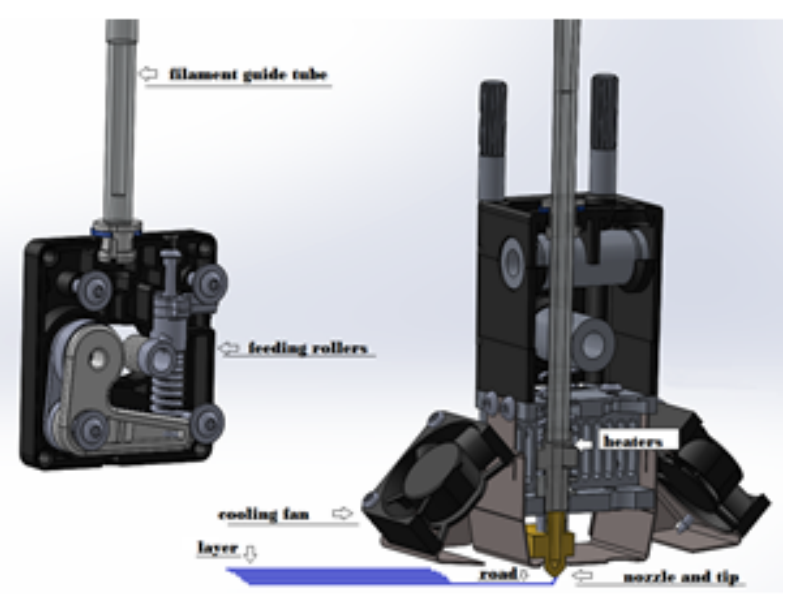

Fig. 1. Extrusion head assembly with section view and the layer by layer 3D printing process
The fundamental analysis of a two-layer cross-ply printed specimen ( a layer with roads at $0^{\circ}$ in the $\mathrm{x}$-direction on top of another layer of the same thickness with roads at $90^{\circ}$ to the $y$ direction) is described below. If the two layers (fig. 2 ) are to form a specimen, certain assumptions are required. The relation between thex-direction stresses in the top and bottom layers is shown by equation (1), while the strain and displacements are defined by equation (2):

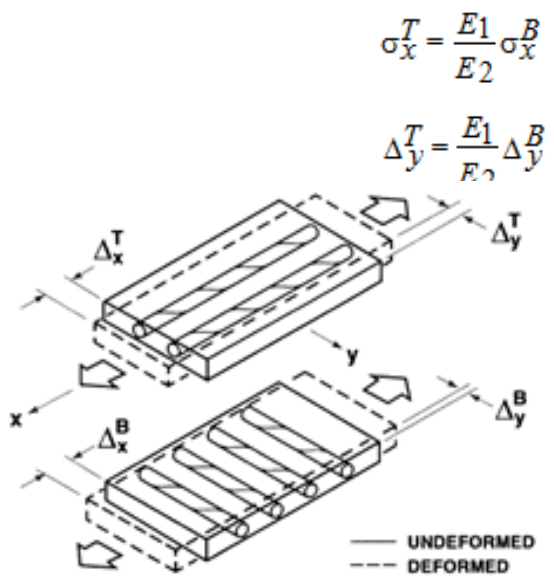

The classical theory enables the reduction of complicated three-dimensional elasticity problem to a solvable twodimensional mechanics of a deformable bodyissue. The study of the stress-strain behavior shows that the stress-strain relations of an orthotropic material under plane stress are:

$$
\left[\begin{array}{c}
\sigma_{1} \\
\sigma_{2} \\
\tau_{12}
\end{array}\right]=\left[\begin{array}{ccc}
Q_{11} & Q_{12} & 0 \\
Q_{12} & Q_{22} & 0 \\
0 & 0 & Q_{66}
\end{array}\right]\left[\begin{array}{c}
\varepsilon_{1} \\
\varepsilon_{2} \\
\gamma_{12}
\end{array}\right]
$$

where the reduced stiffness matrix coefficients used are:

$$
\begin{aligned}
& Q_{11}=\frac{E_{1}}{1-v_{12} v_{21}} ; Q_{22}=\frac{E_{2}}{1-v_{12} v_{21}} ; \\
& Q_{12}=\frac{v_{12} E_{2}}{1-v_{12} v_{21}}=\frac{v_{21} E_{1}}{1-v_{12} v_{21}} ; Q_{66}=G_{12}
\end{aligned}
$$

Defining the strain-stress variations through the thickness of the specimen means integrating the stress-strain relations for each layer throughout the sample. This way the resultant forces and moments will be obtained.

An importanthypothesis used is that the layers are perfectly bonded, and the bonds are infinitesimally thin as well as nonshear-deformable, meaning that the specimen acts as a single layer. We chose to ignore the shearing strains working in XZ and $Y Z$ planes, as they have little influence on the sample for the current study:

$$
\gamma_{x z}=\gamma_{y z}=0
$$

where $\gamma_{x^{\prime}} \gamma_{y z}$ are the angles between the normal and the middle surface of the deformed plane, and $z$ is the normal to the medial surface in figure 3 .

Also, due to the hypothesis of constant thickness we can write $\varepsilon_{z}=0$.

Subsequently, the strains are defined in term of displacements as:

$$
\begin{aligned}
& \varepsilon_{x}=\frac{\partial \mathrm{u}}{\partial x}=\frac{\partial \mathrm{u}_{\circ}}{\partial x}-z \frac{\partial^{2} \mathrm{w}_{0}}{\partial x^{2}} \\
& \varepsilon_{y}=\frac{\partial \mathrm{v}}{\partial y}=\frac{\partial \mathrm{v}_{\circ}}{\partial y}-z \frac{\partial^{2} \mathrm{w}_{0}}{\partial y^{2}} \\
& \gamma_{x y}=\frac{\partial \mathrm{u}}{\partial y}+\frac{\partial \mathrm{v}}{\partial x}=\frac{\partial \mathrm{u}_{0}}{\partial y}+\frac{\partial \mathrm{v}_{0}}{\partial x}-2 z \frac{\partial^{2} \mathrm{w}_{0}}{\partial x \partial y}
\end{aligned}
$$




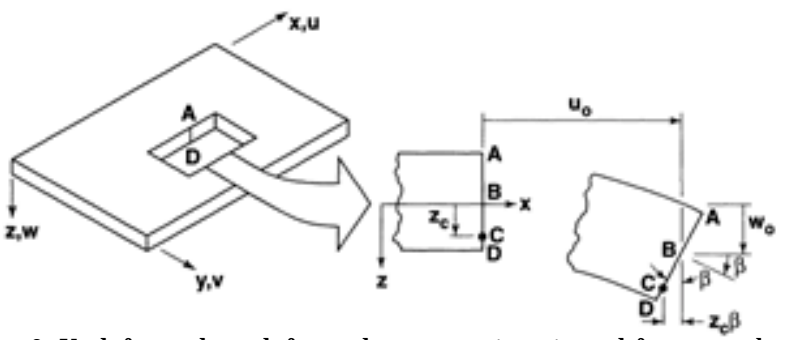

Fig. 3. Undeformed vs. deformed cross section viewed from $x-z$ plane

with $u_{0}$ the movement in the $x$-direction of point $B$ and $w_{0}$ the displacement in the y-direction.

Integrating the stresses in each layer of specimen throughout the laminate, the resultant forces and moments will be obtained.

$$
\begin{aligned}
& \left\{\begin{array}{l}
N_{x} \\
N_{y} \\
N_{x y}
\end{array}\right\}=\int_{-t / 2}^{t / 2}\left\{\begin{array}{l}
\sigma_{x} \\
\sigma_{y} \\
\tau_{x y}
\end{array}\right\} d z=\sum_{k=1}^{N} \int_{z_{k-1}}^{z_{k}}\left\{\begin{array}{l}
\sigma_{x} \\
\sigma_{y} \\
\tau_{x y}
\end{array}\right\}_{k} z d z \\
& \left\{\begin{array}{l}
M_{x} \\
M_{y} \\
M_{x y}
\end{array}\right\}=\int_{-t / 2}^{t / 2}\left\{\begin{array}{l}
\sigma_{x} \\
\sigma_{y} \\
\tau_{x y}
\end{array}\right\} z d z=\sum_{k=1}^{N} \int_{z_{k-1}}^{z_{k}}\left\{\begin{array}{l}
\sigma_{x} \\
\sigma_{y} \\
\tau_{x y}
\end{array}\right\}_{k} z d z
\end{aligned}
$$

The resulting constitutive relations associate the specimens in-plane resultantforces and moments with the middle surface deformations and curvatures through the stiffness matrices $[A],[B]$ and $[D][22]$ :

$$
\left\{\begin{array}{l}
N_{z} \\
N_{y} \\
N_{x y} \\
\hline M_{z} \\
M_{y} \\
M_{x y}
\end{array}\right\}=\left[\begin{array}{lll|lll}
A_{11} & A_{12} & A_{16} & B_{11} & B_{12} & B_{16} \\
A_{12} & A_{22} & A_{26} & B_{12} & B_{22} & B_{26} \\
A_{16} & A_{26} & A_{66} & B_{16} & B_{26} & B_{66} \\
\hline B_{11} & B_{12} & B_{16} & D_{11} & D_{12} & D_{16} \\
B_{11} & B_{22} & B_{26} & D_{12} & D_{22} & D_{26} \\
B_{16} & B_{26} & B_{66} & D_{16} & D_{26} & D_{66}
\end{array}\right]\left\{\begin{array}{c}
\varepsilon_{z}^{0} \\
\varepsilon_{y}^{0} \\
\gamma_{x y}^{0} \\
\kappa_{z} \\
\kappa_{y} \\
\kappa_{x y}
\end{array}\right\}
$$

where $\boldsymbol{A}_{i j}$ is extensional stiffness relating the in-plane forces to the in-plane deformations, $\boldsymbol{B}_{i:}$ is the bending-extension coupling stiffnesses relating the in-plane forces to the curvatures and the moments to the in-plane strains and $\boldsymbol{D}_{\text {. }}$ are bending stiffnesses relating the moments to the curvatures. These stiffnesses are defined as functions of transformed reduced stiffness matrix of the ply in the specimen $(X-Y)$ coordinate:

$$
\begin{aligned}
& A_{i j}=\sum_{k=1}^{N}\left(\bar{Q}_{i j}\right)_{k}\left(z_{k}-z_{k-1}\right) \\
& B_{i j}=\frac{1}{2} \sum_{k=1}^{N}\left(\bar{Q}_{i j}\right)_{k}\left(z_{k}{ }^{2}-z_{k-1}{ }^{2}\right) \\
& D_{i j}=\frac{1}{3} \sum_{k=1}^{N}\left(\bar{Q}_{i j}\right)_{k}\left(z_{k}{ }^{3}-z_{k-1}{ }^{3}\right)
\end{aligned}
$$

The A, B, D matrix elements can be controlled by the number of layers, the ply layups and the angle of the plies in the specimen in such a way that individual items in these matrices can be tailored to be zero, positive or negative, so that different types of couplings between deformations and curvatures can be strengthen, weakened or even eliminated, in a beneficial way for the final structure.

The tested materials used in this study were acrylonitrile butadiene styrene (ABS) and polylactic acid (PLA). The specimens with these types of filaments were printed on an Ultimaker ${ }^{\circledR} 2+$ printer, with a $0.4 \mathrm{~mm}$ printing nozzle. The specimens were computer generated according to the dimensions for the Type I tensile specimens [19]. All samples were printed with a thickness of $6 \mathrm{~mm}$. A two view sketch of the sample and it is dimensions are given in figure 4 .

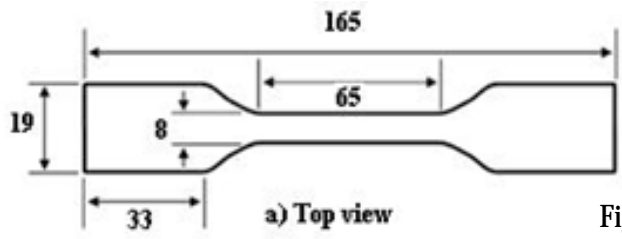

Fig. 4. Schematic representation of

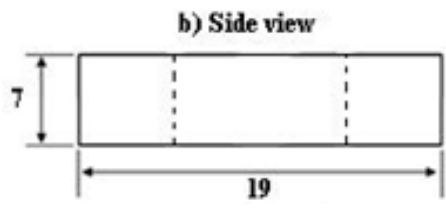
the tensile test specimen with relevant dimensions [in $\mathrm{mm}$ ]

The samples were created in Solidworks $®$, exported as STL format files (Stereo Lithography) and then imported in Cura Software. For the generation of the 3D printer compatible G-code for each specimen some advanced setup parameters w ere used and varied, as can be seen in table 1.

For the printed specimens the width of each road was given by the $0.4 \mathrm{~mm}$ diameter nozzle tip, and the slice height was of $0.1 \mathrm{~mm}$.

Other important and relevant parameters used in the build are presented in table 2 .

\section{Testing machine}

One setup was used for tensile test on every specimen. The samples were subjected individually to uniaxial tension until failure, at room temperature $\left(\sim 23^{\circ} \mathrm{C}\right)$, using an electrohydraulic testing machine equipped with a 100KN load cell. The grips are shown in figure 5 . Each sample was marked around the grips to determine if any sliding occurs visually. Another marking, done with 15 points in the 3D printing process of the specimen, was used to visually identify the displacement of specific points on recorded video data (fig. 6). To prevent any sliding inside the machines grips, new sheets of sandpaper, wrapped around the sample's tabs, were used each time a test was done.

\begin{tabular}{|c|c|c|c|c|}
\hline Material & $\begin{array}{c}\text { Specimen } \\
\text { Type }\end{array}$ & $\mathbf{1}$ & $\mathbf{2}$ & $\mathbf{3}$ \\
\hline ABS & $\begin{array}{c}\text { Wall } \\
\text { thickness }\end{array}$ & 1.4 & 1.4 & 1.4 \\
\hdashline & $\begin{array}{c}\text { Top/Bottom } \\
\text { Thickness }\end{array}$ & 0.9 & 0.9 & 0.9 \\
\hline PLA & Infill density & $0 \%$ & $50 \%$ & $100 \%$ \\
\hdashline & $\begin{array}{c}\text { Wall } \\
\text { thickness }\end{array}$ & 1.3 & 1.3 & 1.3 \\
\hdashline & $\begin{array}{c}\text { Top/Bottom } \\
\text { Thickness }\end{array}$ & 0.9 & 0.9 & 0.9 \\
\hdashline & Infill density & $0 \%$ & $50 \%$ & $100 \%$ \\
\hline
\end{tabular}

Table 1

VARIATIONS OF ADVANCED SETUP PARAMETERS FOR EACH SPECIMEN USED TO GENERATE THE G-CODE 
Table 2

ADDITIONAL SETUP PARAMETERS FOR EACH SPECIMEN USED IN THE BUILD

\begin{tabular}{|c|c|c|}
\hline Parameter & $\begin{array}{c}\text { Ultimaker }{ }^{82+} \\
\text { ABS }\end{array}$ & $\begin{array}{c}\text { Ultimaker \& } \\
\mathbf{2 +} \\
\text { PLA }\end{array}$ \\
\hline Air gap (mm) & 0.0 & 0.0 \\
\hline Slice height (mm) & 0.1 & 0.1 \\
\hline $\begin{array}{c}\text { Extrusion width } \\
(\mathbf{m m})\end{array}$ & 0.4 & 0.4 \\
\hline Nozzle size (mm) & 0.4 & 0.4 \\
\hline Filament color & Gray & Silver metallic \\
\hline $\begin{array}{c}\text { Liquified } \\
\text { temperature }\left({ }^{\circ} \mathrm{C}\right)\end{array}$ & 235 & 150 \\
\hline $\begin{array}{c}\text { Environmental } \\
\text { temperature }\left({ }^{\circ} \mathrm{C}\right)\end{array}$ & 20 & 20 \\
\hline
\end{tabular}

The displacement was measured with an electronic extensometer, with a sampling rate of $100 \mathrm{~S} / \mathrm{s}$, acquired with an NI USB 6008 data acquisition device and processed through the custom developed LabVIEW $\AA$ environment software program. The displacements were measured on one side of the specimen.

For tensile testing, the average stress in the sample, at any given load, was determined by dividing the load by the cross-sectional area. Calculation of the necessary strain data was accomplished through the use of the digital extensometer, a contact measurement technique, and the custom software.

\section{Numerical simulation}

After the tensile testing had been done, the material characteristics were gathered. The data from the ABS samples was used as data input for an ANSYS numerical simulation.

The lower part of an ankle foot orthosis or insole was modeled in ACP module, as a composite structure of variable density and orientation $\left(-45,45^{\circ}\right)$ layers of $A B S$ material, and a finite element analysis with shell elements suitable for analyzing thin to moderately thick structures was done.

The finite element used was a solid element with six degrees of freedom at each node with translations and rotations on and about all three directions $(x, y, z)$.

Treating the ABS specimens as composites required defining the top and bottom layers as well as a core. The upper and lower layers were considered to be composed out of 4 distinct plies with 0,1 thickness, and the next printed filament orientation $(45,-45,45,-45)$ mirrored about the central plane of the specimen. The core was considered to be a honeycomb layered stack up with a total thickness of $2.4 \mathrm{~mm}$ and a 0 degree filament orientation.

Figure 7 shows a mesh with over 100000 layered elements and also the maximum thickness of the specimen provided by the Cura software after taking into

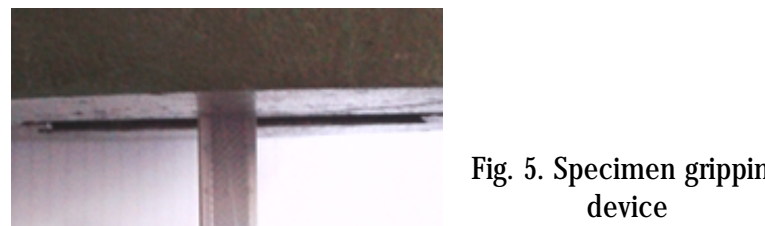

device

Fig. 6. Tensile test specimen printed with face markers for image data gathering

consideration the small filament dilatation due to temperature differences.

A stress analysis of the insole was run under the assumption of a fixed bottom surface of the insole and variable force input (fig. 7) on the footprint corresponding to a $90 \mathrm{~kg}$ bodyweight. The same analysis under the same setup data with the sole modification of material characteristics, from ABS to PLA, was run to gather comparative data.

The differences between the two simulations were minimal; the ABS gave a max equivalent stress on the insole slightly higher than the PLA. However, the primary focus of this analysis was to show the different loading patterns of the insole and to underline that the stress on the foot can be reduced by the proper use of various density layers. The analysis showed that a lower density core could be used for higher pressure areas generated by the dysfunction or orthosis to reduce the pressure on the foot, while higher density layers are to be used to correct the position of the foot and to strengthen the ground contact areas and insole high-stress areas.

\section{Results and discussions}

The stress-strain diagram of the 3D printed and tested specimens are shown in figure 8 . The vertical axis indicates the stress in MPa and the $x$-axis the strain in percent.

A first observation to be made on the diagram is that the curve shapes of the different material specimens are quite similar. The similarity deepens when the same fabrication method is involved.

The stress curves for the hollow core type specimens $\left(\sigma_{\text {ABShC }}, \sigma_{\text {PLAAC }}\right)$, printed with an infill of $50 \%$ are almost mirrored, as are those for the other samples, printed with a $100 \%$ infill. All the curve shapes are showing approximately the same elongation at yield, in proximity to $2 \%$ strain. The corresponding yield strength is between 13 and $15 \mathrm{MPa}$ for

Fig. 7. Footprint color coded force distribution, insole mesh with print cut areas, stress distribution on a multilayered ABS composite

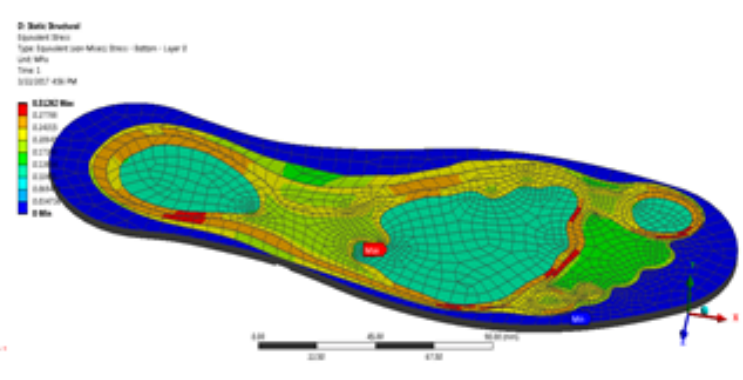




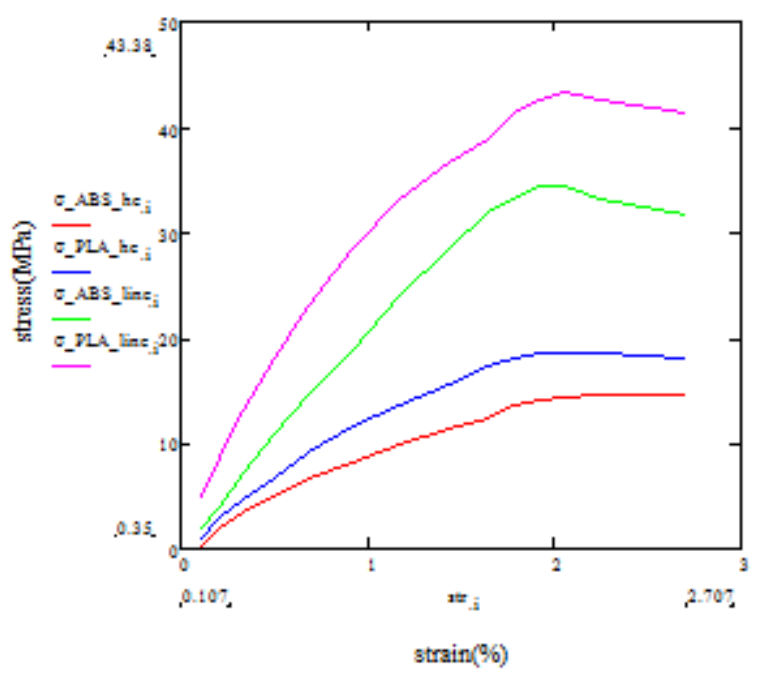

Fig. 8. Stress-strain diagram comparison of ditterent material specimens

the hollow core samples and between 32 to $44 \mathrm{MPa}$ for the full ones. This shows that all the samples are somewhat brittle.

The analysis of figure 8 shows some interesting facts. The hollow core specimens have a higher yield strength of the PLA samples compared to the ABS ones. Considering the samples with $100 \%$ infill, we can say that the PLA have better strength than ABS. Furthermore, a combination of $A B S$ and $100 \%$ infill leads to rather ductile samples.

Comparisons between ABS and PLA samples lead to the conclusion that PLA has up to 1.3 times the strength of ABS. So if the application demands strength, PLA and line pattern is deemed appropriate.

To help offlead high pressures on the foot brought by the use of orthotic devices, it is a good idea to use different mesh densities when printing a $3 \mathrm{D}$ orthotic device. Also, a parametric study of boundary curves to give adjustable orthotic devices is now possible due to the adaptability of the printing technology.

It is evident that different printing areas of the insole with various mesh densities will help offload high pressures from the foot. Correcting the swing and mid-stance phases put pressure on the foot through the orthotic device that can be alleviated with custom density layer 3D printed insoles.

Research undergone in this field is based on the available tensile test methods provided by the ASTM standards and on identifying the tensile properties as a function of build orientations [15, 18, 19, 23, 24]. The authors of recent studies looked into the influence of layer to layer adhesion, road shrinkage because of temperature differences and orientation dependent higher porosity [23, 24] on the parts material properties. Reducing the printed parts anisotropy has been the goal of other scientists that focused on blending differenttypes of polymers for the parts mechanical properties to meetcertain failure criteria [24]. This approach reduced the anisotropy but generated a decrease in overall material strength. It can be said that most studies on mechanical characterization of 3D printed parts provide the yield strength, Young's modulus, and the ultimate strength after tensile tests using extensometers and universal testing machines. Few are those that include the strain energy density, Poisson's ratio or any shear data [2528].

The printed structures based on plastics represent promising future applications in orthosis and prosthesis fields [29-34]. Another important trend is the study of different materials starting from recyclable wasted plastics spread all over the environment in very high amounts [ 3437]. New technologies are used to develop the recycling plastics industry [38, 39]. Health status and human wellbeing will be further improved [40].

\section{Conclusions}

The aim of this article is to offer an experimental and numerical characterization of $3 D$ printed $A B S$ and $P A L$ specimens using a universal traction-compression testing machine. After the material data has been gathered, a numerical study using ACP module of ANSYS 16.0 is undertaken to compare samples printed under differentinfill percentages and to explore the way this affects the material strength and its implication in orthosis development are regarded through data comparison. A novel approach is offered by treating the specimen as a composite material and each printing layer as a ply. The advantages and challenges of such a proposition are then discussed.

Several experiments were conducted on different 3D printed ABS and PLA specimens with a stack-up configuration to characterize their tensile properties and mechanical behavior. The experimental values obtained are used in an ANSYS software simulation with finite elements of a 3D printed insole. A series of meaningful conclusions can be drawn: the highest strength of the four types studied determined for the full filled PLA specimens and recorded at 44.24MPa, for the custom prints at room temperature; or that the numerical results are in good agreement with the experimental test values obtained. We can also state that the numerical simulation employed specialized software and finite element analysis by use of ACP module of ANSYS. The accuracy of the numerical solution is given by the high-density mesh and the fact that the use of tools needed for composite materials study, such as numerous layers, materials and ply orientations, has been employed for the study of $3 d$ printed layered specimens. We estimate that the offlead of high pressures on the foot brought by the use of different mesh densities when printing a 3D orthotic device can have an impact of up to $25 \%$ on alleviating the foot stress.

Acknowledgements: This study is a contribution to the PhD thesis Functional neuromotor reeducation of the operated paralytic disc herniation, no. 3110, which took place in Grigore T. Popa University of Medicine and Pharmacy - lasi.

\section{References}

1.MEDICAL RESEARCH COUNCIL, Her Majesty's Stationery Office, London, 1981.

2.GHAHREMAN, A., FERCH, R.D., RAO, P., CHANDRAN, N., SHADBOLT, B., J. Clin. Neurosci., 16, No. 8, 2009, p. 1024.

3.IIZUKA, Y., IIZUKA, H., TSUTSUMI, S., NAKAGAWA, Y., NAKAJIMA, T., SORIMACHI, Y., ARA, T., NISHINOME, M., SEKI, T., SHIDA, K., TAKAGISHI, K., J. Neurosurg.-Spine, 10, No. 3, 2003, p. 260.

4.GUIGUI, P., BENOIST, M., DELECOURT, C., DELHOUME, J., DEBURGE, A., J. Spinal Disord., 11, No. 4, 1998, p. 283.

5.MARICONDA, M., GALASSO, O., SECONDULFO, V., COZZOLINO, A., MILANO, C., J. Bone J oint. Surg. Br., 90B, No. 5, 2008, p. 622.

6.STEWART, J.D., Pract. Neurol., 8, 2008, p. 158.

7.CHU, T.M., J. Rehabil. Res. Dev., 4, 1995, p. 349.

8.BREGMAN, D.J.J., DE GROOT, V., VAN DIGGELE, P., MEULMAN, H., HOUDIJK, H., HARLAAR, J., Prosthet. Orthot. Int., 34, No. 3, 2010, p. 293.

9.HARLAAR, J., BREHM, M., BECHER, J.G., BREGMAN, D.J ., BUURKE, J., HOLTKAMP, F., DE GROOT, V., NOLLET, F., Prosthet. Orthot. Int., 34, No. 3, 2010, p. 327.

10.KOBAYASHI, T., LEUNG, A.K., HUTCHINS, S.W., J. Rehabil. Res. Dev., 48, No. 5, 2011, p. 565.

11.EARAR, K., BICA, C., CERGHIZAN, D., ILIE, M., Mat. Plast., 53, no. 3, 2016, p. 512. 
12.EARAR, K., CERGHIZAN, D., SANDU, A.V., MATEI, M.N., LEATA, R., SANDU, I.G., BEJINARIU, C., COMAN, M., Mat. Plast., 52, no. 4, 2015, p. 487.

13.EARAR, K., MATEI, M.N., SANDU, A.V., HRISTIAN, L., BEJ INARIU, C., SANDU, I.G., Mat. Plast., 52, no. 1, 2015, p. 98.

14.MATEI, M.N., EARAR, K., TRINCA, L.C., MARECI, D., FOTEA, L., PEPTU, C.A., BICA, C., Rev. Chim. (Bucharest), 67, no. 4, 2016, p. 800. 15.BELLINI, A., GUCERI, S., Rapid Prototyping J., 9, No. 4, 2003, p.252. 16.BOLDUREANU, G., BOLDUREANU, D., et al, The Yearbook of the Gh. Zane Institute of Economic Researches, 20, 2011, p. 79.

17.BOLDUREANU, D., PRODAN, A., ANDRUSEAC, G.G., COSTULEANU, C.L., BOLDUREANU, G., 8th International Conference on Education and New Learning Technologies, EDULEARN 2016, 4-6 JULY 2016, Barcelona, Spain, EDULEARN16 Proceedings, ISBN: 978-84-608-8860-4, 2016, p. 9116.

18.GIANNATSIS, J., et al., Proceedings of the 5th International Conference on Advanced Research and Rapid Prototyping, 2012, p. 525.

19.HILL, N., HAGHI, M., Rapid Prototyping J ., 20, No. 3, 2014, p. 221. 20.TYMRAK, B.M., KREIGER, M., PEARCE, J.M., Mater. Design, 58, 2014, p. 242.

21.ASTM D638, Standard test method for tensile properties of plastics, 2002.

22.BUZDUGAN, G., Rezistenta materialelor, Ed. Academiei, Bucuresti, 1986.

23.TORRADO, A.R., SHEMELYA, C.M., ENGLISH, J.D., LIN, Y., WICKER, R.B., ROBERSON, D.A., Addit. Manufact., 6, 2015, p.16.

24.ES-SAID, O.S., FOYOS, J., NOORANI, R., PREGGER, B.A., Mat. Manufact. Proc., 15, No. 1, 2000, p. 107.

25.AHN, S.H., BAEK, C., LEE, S., AHN, I.S., Int. J. Mod. Phys. B, 17, No. $8-9,2003$, p. 1510.

26.AHN, S.-H., ODELL, D., ROUNDY, S., W RIGHT, P.R., Rapid Prototyping J., 8, No. 4, 2002, p. 248.
27.MONTERO, M., ROUNDY, S., ODELL, D., Proceedings of Rapid Prototyping and Manufacturing Conference, 2001, p. 1.

28.CANTRELL, J., ROHDE, S., DAMIANI, D., GURNANI, R., DISANDRO, L., ANTON, J., YOUNG, A., JEREZ, A., STEINBACH, D., KROESE, C., IFJU, P., Proceedings of the 2016 Annual Conference on Experimental and Applied Mechanics (S. Yoshida, L. Lamberti, and C. Sciammarella, eds.0, vol. 3, Cham: Springer International Publishing, 2017, p. 89. 29.GRECU, D., ANTONIAC, I., TRANTE, O., NICULESCU, M., LUPESCU, O., Mat. Plast., 53, no. 4, 2016, p. 776.

30.MICLAUS, R., REPANOVICI, A., ROMAN, N., Mat. Plast., 54, no. 1, 2017, p. 98.

31.SINESCU, C., NEGRUTUI M.L., ROMINU, R.O., RUSU, L.C., TOPALA, F.I., ROMINU, M., ARDELEAN, L., PODOLEANU, A., Mat. Plast., 49, no.1, 2012, p. 58.

32.PRICOP, M., BALESCU, H., ROSU, S., URECHESCU, H., CRAINICEANU, Z., Mat. Plast., 53, no. 1, 2016, p. 79.

33.PAHONIE, R.C., STEFAN, A., COSTULEANU, C.L., BOLDUREANU, D., ANDRUSEAC, G.G., Mat. Plast., 54, no. 1, 2017, p. 155.

34.COSTULEANU, C.L., BOLDUREANU, G., ANDRUSEAC, G,G., Rev. Chim. (Bucharest), 68, no. 5, 2017, p. 1058.

35.COSTULEANU, C.L., BREZULEANU S., IGNAT, G., BOLDUREANU, G., TOMA, M.C., ANDRUSEAC, G.G., Rev. Chim. (Bucharest), 67, no. 10, 2016, p. 1990.

36.COSTULEANU, C.L., BOBITAN, N., DUMITRESCU, D., Environ. Eng. Manag. J., 14, No. 6, 2015, p. 1423.

37.COSTULEANU, C.L., VINTU, C.R., ROBU, D.A., IGNAT, G., BREZULEANU, S., Rev. Chim. (Bucharest), 66, no. 5, 2015, p. 743.

38.IGNAT, G., COLIBABA, C., COSTULEANU, C.L., BALAN, A., ROTARU, L., SANDU, I.C.A., Mat. Plast., 53, no. 3, 2016, p. 367.

39.IGNAT, G., BALAN, G., SANDU, I., COSTULEANU, C.L., VILLE, S.T.S., Rev. Chim. (Bucharest), 67, no. 8, 2016, p. 1560.

40.COSTULEANU, C.L., DUMITRESCU, D., BREZULEANU, S., BOBITAN, N., Rev. Cercet. Interv. Soc., 48, 2015, p.50.

Manuscript received: 15.12 .2016 